\title{
Gated Radiotherapy Development and its Expansion
}

\author{
Mohammad Javad Keikhai Farzaneh", ${ }^{1,2}$, Mehdi Momenn- \\ ezhad ${ }^{1,3 * \odot}$, Shahrokh Naseri ${ }^{1,4}$
}

\begin{abstract}
One of the most important challenges in treatment of patients with cancerous tumors of chest and abdominal areas is organ movement. The delivery of treatment radiation doses to tumor tissue is a challenging matter while protecting healthy and radio sensitive tissues. Since the movement of organs due to respiration causes a discrepancy in the middle of planned and delivered dose distributions. The moderation in the fatalistic effect of intra-fractional target travel on the radiation therapy correctness is necessary for cutting-edge methods of motion remote monitoring and cancerous growth irradiancy. Tracking respiratory milling and implementation of breath-hold techniques by respiratory gating systems have been used for compensation of respiratory motion negative effects. Therefore, these systems help us to deliver precise treatments and also protect healthy and critical organs. It seems aspiration should be kept under observation all over treatment period employing tracking seed markers (e.g. fiducials), skin surface scanners (e.g. camera and laser monitoring systems) and aspiration detectors (e.g. spirometers). However, these systems are not readily available for most radiotherapy centers around the word. It is believed that providing and expanding the required equipment, gated radiotherapy will be a routine technique for treatment of chest and abdominal tumors in all clinical radiotherapy centers in the world by considering benefits of respiratory gating techniques in increasing efficiency of patient treatment in the near future.

This review explains the different technologies and systems as well as some strategies available for motion management in radiotherapy centers.
\end{abstract}

Citation: Keikhai Farzaneh MJ, Momennezhad M, Naseri Sh. Gated Radiotherapy Development and its Expansion. J Biomed Phys Eng. 2021;11(2):239-256. doi: 10.31661/jbpe.v0i0.948.

\section{Keywords}

Breast Neoplasms; Radiotherapy, Conformal; Radiotherapy; Respiratory Gated Radiotherapy; Tumor Tracking

\section{Introduction}

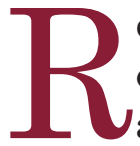

espiration is the process of exchanging oxygen with carbon dioxide in the lungs. The contraction and relaxation of the muscles around the lungs lead to periodic motion of the lungs in the some phases, including breathing, inhalation and exhalation [1]. It has been shown that the pattern of respiratory motion is patient dependent [2] and breathing travel models could change between fractions and also into a fraction [3]; thus, there is not any common respiratory manner that can be considered for a particular patient before observing [4].

Furthermore, contraction and relaxation of respiratory muscles, along with changes in lung volume, will cause the movement in some internal organs in abdominal and chest areas. The numerous studies aim to
${ }^{1} \mathrm{PhD}$, Department of Medical Physics, Faculty of Medicine, Mashhad University of Medical Sciences, Mashhad, Iran

${ }^{2} \mathrm{PhD}$, Department of Medical Physics, Faculty of Medicine, Zahedan University of Medical Sciences, Zahedan, Iran ${ }^{3} \mathrm{PhD}$, Nuclear Medicine Research Center. Mashhad University of Medical Sciences, Mashhad, Iran

${ }^{4} \mathrm{PhD}$, Medical Phys-

ics Research Center, Mashhad University of Medical Sciences, Mashhad, Iran

*Corresponding author: Mehdi Momennezhad Medical Physics Department, Faculty of Medicine, Mashhad University of Medical Sciences, Pardis-e-Daneshgah, Vakil Abad Blvd., Mashhad, Iran

E-mail: momennezhadm@mums.ac.ir

Received: 17 May 2018 Accepted: 14 July 2018 
investigate movement of internal organs, due to the breathing procedure. A research carried out by Langen et al. has investigated the movements of lung, diaphragm, rectum, liver, bladder, prostate and pancreas owing to breathing [5]. These studies show that many factors, including tumor location, tumor pathology and general health of patients can affect the motion of internal organs and also there is not any specific general patterns, for movement of internal organs arising from respiration, for all purposes [6]. According to these studies, internal organs have the largest displacement, as a result of respiratory procedure, in superiorinferior orientation. Moreover, there is a much smaller displacement in lateral and anteriorposterior orientations. Average, standard deviation and the maximum displacements in these directions are provided for a number of organs in Table 1 [6].

Furthermore, Liu et al. have shown that in $40 \%$ of patients who are battling with lung cancer, tumor experience a motion some greater than $5 \mathrm{~mm}$. They have also find out that lung tumors of around $\% 12$ of lung cancer patients move further than $10 \mathrm{~mm}$ [7]. Nevertheless, some organs such as liver, kidneys, pancreas and spleen which are located in the upper abdomen move considerably as a consequence of aspiration, commonly greater than $10 \mathrm{~mm}$ $[5,8]$.

Movement managing is suggested based on patient-characteristic, for tumor motion more than $5 \mathrm{~mm}$ in every orientation [4]; in addition, remarkable efforts are made to determine patient-particular cancerous cells excursion applying tumor location [9, 10], implanted fiducial markers $[11,12]$, the organ in which tumor is located [13], or explore other portions of the body assumed to be correlated to cancerous growth excursion,(i.e., abdomen surface and diaphragm) [14-16]. All efforts aim to increase local control of tumor $[7,9]$.

The effects of internal organ motion caused by respiratory procedure can be viewed by three categories of diagnostic imaging, treatment planning as well as delivery.

\section{Diagnostic imaging}

Blurring and fading are made at diagnostic imaging due to any kind of body motion within the field of view. Breathing caused movements could lead up artifacts at magnetic resonance imaging, cone-beam computed tomography, positron emission tomography and computed tomography images. Since the time of image acquisition per slice is commonly less than 1 second and this time is a fraction of one respiratory period. Although it seems that a single slice is not influenced by breathing movement, sequential sections happen in various phases of breathing period lead to faults in the visible figure, position, size, and volume of body organs $[9,17,18]$. For instance, in nuclear

Table 1: Average, standard deviation and the maximum of the peak to peak displacement of some internal organs as a result of respiratory procedure

Displacement $(\mathrm{mm})$

\begin{tabular}{|c|c|c|c|c|c|c|c|}
\hline & & & & & & & \multirow{3}{*}{$\begin{array}{l}\text { Maximum displacement in the } \\
\text { direction of } \mathrm{SI}\end{array}$} \\
\hline \multirow[t]{2}{*}{ Organ } & \multicolumn{3}{|c|}{ Average } & \multicolumn{3}{|c|}{ Standard deviation } & \\
\hline & SI & AP & $\mathbf{L}$ & SI & AP & $\mathbf{L}$ & \\
\hline Lung & 11.8 & 4.7 & 3.2 & 12.6 & 2.3 & 2.1 & 50 \\
\hline Liver & 25.6 & --- & --- & 14.5 & --- & --- & 55 \\
\hline Kidney & 30.0 & --- & --- & 23.2 & --- & --- & 86 \\
\hline Pancreas & 40.3 & --- & --- & 24.9 & --- & --- & 80 \\
\hline Diaphragm & 35.7 & --- & --- & 29.5 & --- & --- & 99 \\
\hline
\end{tabular}

SI: superior-inferior, AP: anterior-posterior, L: lateral 
medicine imaging, the image shows cumulative activity at time of image acquisition [19], and even a small movement could cause a significant blur in comparison with the intrinsic resolution of the nuclear scanner. Therefore, advancement in the technology to elevate special resolution of nuclear medicine imaging systems is not reasonable until a proper motion correction technique for improvement of resolution can be used. Similarly, it should be considered that respiratory motion can lead to artifact and uncertainties in acquired images depending on different elements such as frequency and amplitude of organs movement. Moreover, these upshots in diagnostic images navigate to skepticism in localization of tumors as well as radiosensitive organs. It can also have an impact on election of planning borders and tackling of inhomogeneities. Cancerous growth territorialisation in image guided radiation therapy (IGRT) is impressed.
Consequently, respiratory movement can reduce the accuracy of treatment planning as well as treatment delivery. Breathing caused movements should be confronted in all stages of treatment planning and delivery [20].

\section{Treatment Planning}

External radiation therapy aims to delivery prescribed dose to cancerous growth so that the normal cells surrounding the tumor have the minimum absorbed dose. However, owing to the complex structure of tumors and the surrounding tissues, scattering of the primary beams as well as organ motions, attaining to this aim is difficult. Figure 1 shows a treatment planned theoretical image of a tumor and its surrounding tissues. In this image, Biological Tumor Volume (BTV) will be delineated by images of Positron Emission Tomography (PET) or single photon emission computed tomography and Gross Tumor Volume (GTV)

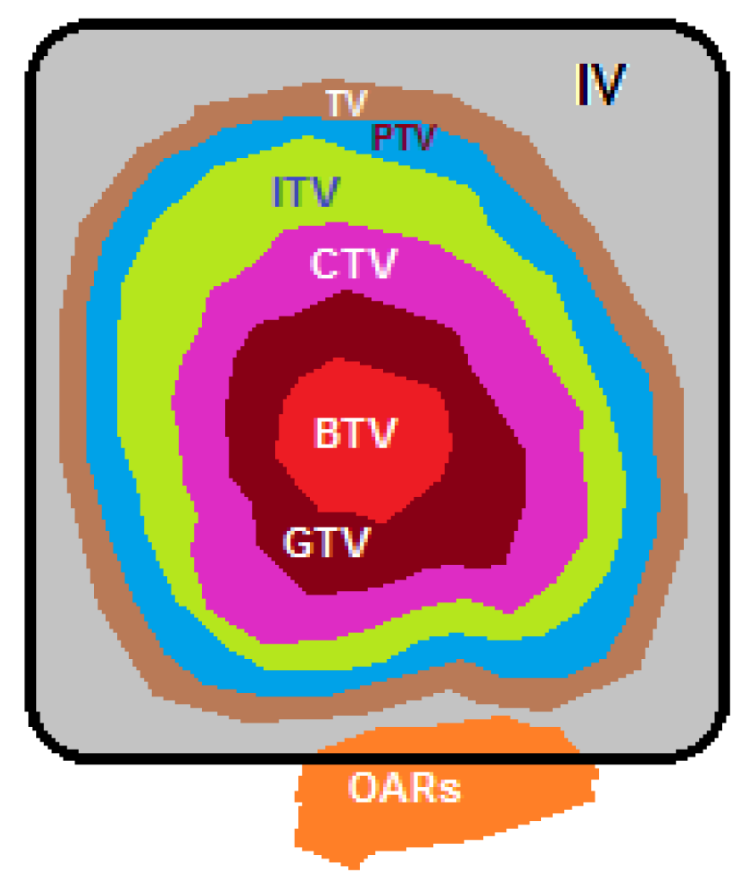

Figure 1: Schematic image of treatment planning volumes in external beamradiation therapy. Biological Tumor Volume (BTV), Gross Tumor Volume (GTV), Clinical Target Volume (CTV), Internal Target Volume (ITV), Planning Target Volume (PTV), Treated Volume (TV), Irradiated Volume (IV) and Organ at Risk (OARs). 
will be specified by computed tomography or magnetic resonance imaging with high spatial resolution. At the next, a medical oncologist will delineate the Clinical Target Volume (CTV) as well as Planning Target Volume (PTV) based on microscopic tumor spread, organ motions as well as systematic and random errors related to setup of the patient. The concept of internal target volume (ITV) was introduced in report 62 of ICRU (International Commission on Radiation Units and Measurements) for tumor movement consideration [21]. ITV is determined as the clinical target volume (CTV) plus an extra border count geometric doubts of respiration, heart beating as well as movement of the bowel. Moreover, it calculates tumor size and shape alterations. For ITV determination of a tumor located in the chest wall, firstly, GTV delineates in different respiratory bins including the four-dimensional computed tomography, MR or PET imaging. Secondly, GTV expands to CTV for consideration of microscopic disease and finally ITV defines for covering CTV movements [21].On the other hand, in the lack of movement recompense, borders must be greater $(10-20 \mathrm{~mm})$ to minimize the target lost opportunity due to the movement [22].

Although, adding an extra margin to CTV for determination of PTV reduces the error caused by the tumor motion, this policy increases the risk of higher dose delivery to normal tissues and organ at risk (OAR) tissues. Therefore, many researchers have surveyed different methods and techniques with the aims of patient motion correction, PTV minimization, more protection of organs at risk and maximization of dose delivery to tumor tissues [23, 24].

\section{Treatment Delivery}

However, evaluating the impacts of breathing movement is essential for treatment planning, it might not be adequate for treatment delivery. Breathing could change in amplitude and period from time to time; shifting base- line, position shift of a curve evaluated upon multiple cycles (consisting breathing, organ or tumor tract), can be happened and phase relevancy from one anatomical site to another can change. While measuring breathing movement and factors can act on it for every patient, the expanse of incertitude is crucial. For example, baseline shifts are especially problematic [25-27] and $2 \mathrm{~mm}$ baseline alteration is anticipated to be sufficiently rectified by a $5 \mathrm{~mm}$ border for movement [28]. In spite of the fact that breathing is commonly uneven, the termination of exhalation phase is rather constant and minor affected by the uneven behavior. In addition, people usually spend more time on close end exhalation than close other phases [10, 26, 29]. Thus, the CT50 or end exhalation phase is frequently applied for contouring, planning and assessment. Nevertheless, at the end of expiration, the volume of the lung is minimum and therefore, the portion of lung obtaining a certain dose will be larger.

Lastly, involuntary movement and displacement of the tumor as well as its surrounding healthy tissues during dose delivery (intrafraction motion) and between different treatment sessions (inter-fraction motion) can lead to alteration of dose distribution. Therefore, monitoring and, if possible, controlling the amplitude of these involuntary movements have been considered and analyzed in a number of radiotherapy studies [30, 31].

\section{Material and Methods}

\section{Tracking Target movement}

As already noted, compensation of the effects arising from the organ motion due to respiration has a particular importance in diagnostic imaging and radiotherapy treatments. However, we can find appropriate techniques for compensation of the adverse effects caused by organ motion, there is a need to track and monitor the movements. Methods of monitoring and gating of the organ motion can be evaluated and studied in the two categories of 
internal target tracking and gating based on as well as external surface tracking and gating based on.

Internal target tracking and Gating based on

Many studies have been carried out for tracking and monitoring of internal organ movements, during image acquisition in diagnostic imaging as well as dose delivery in external beam radiotherapy. Some of the most important gating methods based on internal target tracking are explained further.

\section{Fluoroscopy}

One of the most efficient tracking methods is planting a fiducial marker within or near the target tissue and then monitoring this marker via fluoroscopy images. For implementation of this technique, an extensive diversity of fiducial markers for various parts of the body and clinical applications have been designed and manufactured, but implantation of these markers inside the body is invasive method and associated with a possible risk of putridity $[32,33]$. In addition, it should be considered that the entry of fiducial markers by bronchofiberscopy is safe and feasible for peripheral pulmonary tumors and difficult for central pulmonary tumors [34, 35]. Similarly, piercing the chest wall to implant the fiducial marker may lead to pneumothorax in some cases [34, 35].

One of the most important evolutions for tracking internal body tumors was the invention of Mitsubishi / Hokkaido Real-Time Tumor-Tracking (RTRT) system using simultaneous tracking of implanted gold markers inside the tumor via fluoroscopy images [11, 12, 35-38]. The RTRT system was designed and built in 1998 and also installed at the Hospital of Hokkaido University in Japan. This system uses four image intensifying amplifiers and four X-ray tubes mounted on the roof of Linac room and upon the floor of Linac room, respectively, in order to obtain fluoroscopy images from different angles for determining the three-dimensional positions of implanted fiducial markers inside the patient's body. Afterwards, only when the fiducial marker is on the predetermined gate, a command of exposing will be given to the linear accelerator [39, 40]. The strong point of RTRT internal gating systems is precision. It also provides a real time determination of tumor location during radiotherapy treatment while getting coupled with Image Guided Radiotherapy (IGRT) localization [41]. However these gating systems are criticized by many researchers. According to the research of Imura et al. [42], the relationship between location of implanted fiducial marker in the bronchial branches and tumor site can have experienced considerable changes after two weeks of implantation. It is noteworthy that tracking and monitoring an inner body tumor is very difficult without using fiducial markers and only via fluoroscopy images and in many cases is not possible [42]. Additionally, this system uses a fluoroscopy modality for imaging and tracking tumor location and this imposes an extra dose on the patient. Moreover, planting of fiducial markers is not possible for some tumor locations such as pulmonary tumors because of pneumothorax risk [12]. Therefore, owing to these concerns, few radiotherapy centers in the world are using the RTRT system in order to perform the respiratory gating technique [12]. Figure 2 shows the concept of real-time tumor-tracking in radiotherapy.

4D CT

Another procedure toward internal body movement watching is motion correlated with CT or 4D CT. A 4D CT data set contains many 3 dimensional images demonstrating a different bin of the breathing period. Binning modes applied are either phase binning- relating every 3D CT image with a fraction or phase of respiratory cycle- or magnitude binning - relating every 3D CT image with a portion of the whole respiratory magnitude. Every 3D image of 4D CT image group has a specific phase or deduction of magnitude. Mostly, the group of 4D CT image contains 10 various 3D CTs. 


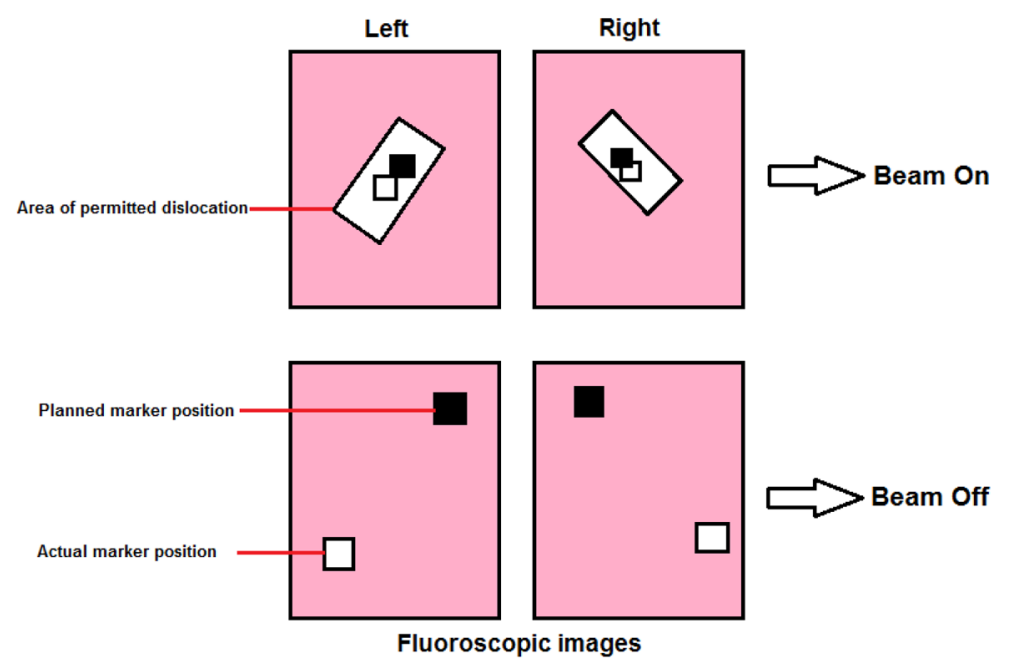

Figure 2: The sense of real-time tumor-tracking in radiation therapy. The projected location of the planned and real 3 dimensional coordinates of the marker could be observed on the corresponding fluoroscopic image. When the planned and actual positions of the marker occur simultaneously within the allowed displacement, the therapy beam is on. While the actual location of the marker is out the allowed displacement area, the treatment beam is off.

Asymmetrical breathing builds the attainment of high-quality 4D CT images so difficult [43]. Binning way of CT images based on breathing signal could have an impact on the image quality 4D CT.

Phantom study of Abdelnour et al. has shown that "consistency error" (which they define as a measure of the ability to correctly bin over repeated cycles: average binning error \pm standard deviation within one bin) is ranged from $11 \% \pm 14 \%$ to $20 \% \pm 24 \%$ for amplitude binning and from $18 \% \pm 20 \%$ to $30 \% \pm 35 \%$ for phase binning [44]. This study concluded that amplitude binning, bins the images more accurately, but it is more sensitive to irregular respiration, specially to magnitude irregularities that can cause gaps on the images [44].

\section{EPID}

Another strategy for tracking inner body tumors in radiotherapy treatment rooms is the use of an Electronic Portable Imaging Device (EPID). Although the use of EPID prevents from imposing additional imaging doses to the patient, the resolution of the derived images by EPID is much lower than the images acquired by fluoroscopy systems due to the use of high energy for image acquisition in EPID [45]. Currently, research and investigation on this method has been in progress.

Fiducal electromagnetic transponders Implantation of an Electromagnetic Transponder (EMT) inside the body, in order to track internal tumors, has been examined in several studies. In this method, an electromagnetic transponder, in order to receive a radiofrequency signal and send a different signal, is implanted inside the body. Simultaneously, an antenna is utilized outside the body for tracking the location of the transponder [46, 47]. These techniques are able to measure the tumor position in real-time in the course of treatment and improve patient positioning.

TULOC system, that is successfully examined in PSI for the proton treatment of mobile tumors has been using this method [48]. It utilizes a periodic magnetic field to transfer data between a field generator and a tiny implantable transducer located near the moving can- 
cer lesion. TULOC system uses six differential coils as a field generator and a tiny induction winding covered with slim pad of combinatorial substances as an implantable sensor [48]. Depending on the sensor orientation, the angular accuracy of the TULOC system is $0.5-1^{\circ}$ and the spatial accuracy of it is 1-2 $\mathrm{mm}$ [48]. It should also be considered that, although this method prevents from imposing extra doses due to the imaging procedure to patients, this method does not provide any information about the anatomy around the transponder. Therefore, three-dimensional information, such as images of cone beam CT, should be used to perform conformal radiotherapy treatments, in some Image Guided Radiotherapy (IGRT) systems.

Lastly, using electromagnetic tracking systems is underway especially in particle treatment centers, but patient's sensor insertion via biopsy needle or catheter is an invasive procedure and can cause side effects.

\section{ExacTrac ${ }^{\circledR}$ Adaptive Gating system}

The ExacTrac ${ }^{\circledR}$ Adaptive Gating system includes X-ray imaging system for detection and correction of tumor position alteration in real-time. The system has also an optical infrared tracking system for respiratory gating. In the X-ray imaging system, two detectors have been installed on the ceiling and two X-ray tubes have been housed within the floor of linear accelerator room, and the angel among the two X-ray tube-detector mates is about $90^{\circ}$. Stereoscopic X-ray can be taken at the gating window for confirmation of tumor position both before and during treatment procedure. For gating radiotherapy by ExacTrac $\AA$ Adaptive, fiducial marker implantation is necessary.

4 dimensional $\mathrm{CBCT}$ imaging

A linear accelerator integrated with a cone beam computed tomography (CBCT) scanner can also be a strong gadget for movement monitoring of organs as well as tumors on the therapy couch. Breathing associated with CBCT consists of retrospectively assorting images in layout area yielding subdivision of layout images that each of them correlates with a given respiratory phase. These subdivisions are next reconstructed to figure a collection of 4D CBCT images. Provided fiducials are seeded within target and CBCT localizes targets more accurately. Next, planar images could localize the target and provide essential information about probable deformation and neighbor organs at risk [49]. Purdie et al. made the alteration of a lung target against the time between primary and repeated CBCT. They figured out that after passing 34 minutes, the movement becomes bigger [50]. Higgins et al. evaluated diverse inter-fraction imaging protocols, providing CBCT imaging on a daily basis was essential. They inferred setup margin of 3-4 mm for implementation of daily CBCT as well as 5-9 mm for less often CBCT accomplishment than each fraction [51].

4 dimensional PET/CT imaging

4D PET/CT scans could use for adding breathing correlated functional images to $4 \mathrm{D}$ CT images. After acquisition of 4D CT images, a 4D PET scan is obtained in gating modality. Breathing period is separated into phase bins of adequate time according to breathing signal, and every signal of the PET is associated with its affiliated phase. 4D PET/CT modality is demonstrated as a possible procedure for correction of respiratory movement artifacts in PET images containing an increase in measured SUV, and improves accuracy of PET to CT co-registration, and also reduces smearing [23, 52, 53].

\section{4 dimensional MR imaging}

4D MR imaging is another way for imaging of organ movements located in the abdomen [54]. Cai et al. compared 2D cine images of a phantom with 4D MR images and figured out that the perfect accordance is within $1 \mathrm{~mm}$ [55]. 4D MRI is also utilized for determination of movement for some other treatment locations such as the lung [56], liver [57], and abdomen [58, 59]. Hu et al. utilized from an external bellow to track breathing and provoke image acquisitions at predefined magnitude of 
breathing procedure [54]. Moreover, Breathing signal is linked to each image so that it can be sorted into the suitable breathing phase resulting in a 3D MR image for every breathing phase [54].

Ultrasonic tumor localization

Amongst non-ionizing and non-invasive movement tracking systems, ultrasound-relying systems definitely merit consideration. They are basically exploited for inter-fractional assessment of prostate position [60-62]. In addition, researchers have been working on accomplishment of this technique for liver cancer monitoring along with breathing movement [63]. Real-time volumetric imaging of targets and its surrounding soft tissues can be performed during radiotherapy treatment by means of remotely operated ultrasound system. The system, unified with Linac, is formerly constructed and tested prosperously [61]. Ultrasound-relying device called BAT is a commercially constructed system for dealing with patient status alterations and prostate movability resulted from organ movement [62].

External surface tracking and Gating based on

Monitoring respiration is necessary for determining its impacts on cancerous growth as well as critical organ movements. Free-respiration is not stable in amplitude and period and makes anticipating breathing movement difficult and also limits utility of respiratory assessments [64]. As mentioned in Section 2-1-1, Planted fiducials could monitor cancerous growth and critical organ movements; but, these invasive methods have intrinsic hazards and could not be used in various situations [22]. A method amending respiratory reproducibility could modify tracking and assessment of breathing. Applying external surrogates for following respiration avoids intrinsic hazards of implanting fiducials. Navigating, while tracking chest wall or lung tidal volume, has been illustrated to modify the reproducibility of breathing procedures [65,
66]. Numerous studies have been conducted to develop new equipment for monitoring the respiratory cycle and body movement during diagnostic imaging and external radiotherapy [24, 67, 68]. Pneumatic devices and a device, for tracking the vertical position of the external body surface via infrared reflective markers, have been designed to track respiratory motions [69]. Moreover, some investigators have focused on developing tracking systems without any markers such as the three-dimensional imaging system for body surface area imaging (Galaxy, LAP Laser, Luneburg, Germany) [70] and 4 dimensional laser cameras [71]. This equipment produces a three-dimensional network (3D mesh) from the patient's chest wall as a function of time for diagnostic and therapeutic applications. Despite the fact that many items of this equipment are capable of producing a correct respiratory pattern, its use is not common in radiotherapy clinics.

Various external sensors such as combination of air-bag and strain-gauge sensors or the use of radar systems or infrared sensors have been also surveyed and studied, from 1989 to 2017 , in order to gauge respiratory motion monitoring of patients [72-78]. In the meantime, Kubo et al. in the California University reported the first study in 1995, on implementation of external respiratory gating, using the obtained signal from the external body surface of patients, which had been used in the Varian 2100C linear accelerator [79]. In 2000, they also reported an innovation of a new respiratory gating system used a video camera for tracking infrared reflective markers located upon the abdomen of patient [80]. This system, with the name of Real-Time Positioning Management (RPM) system, was later commercialized by the Varian Company and used and also evaluated in many radiotherapy centers [81-87]. At the same time, similar studies were conducted in radiotherapy centers using Elekta AB linear accelerator for treatment of patients. Traveling waveguides used in Elekta linear accelerators were found not to be as ef- 
ficient and suitable for creating narrow respiratory gated windows as standing waveguides of Varian linear accelerators, thus breath-hold techniques by use of spirometry devices were examined to implement respiratory gating via the Elekta linear accelerators. Therefore, through the use of breath-hold techniques, an Elekta linear accelerator could be continuously on exposure mode for longer time [88, 89].

In addition to studies concentrated on therapeutic dose delivery by a static beam from 2001 to 2016, some studies have been done to track the motion of tumors by dynamic beams. The goal of this method is real-time tracking and exposing of the tumor location by therapeutic beam. However, studies conducted by Hoisak et al. [90] in 2004, Nøttrup et al. [16] in 2007 and Sawant et al. [91] in 2010, show that dynamic real-time tumor tracking and exposing need a motion management strategy which is complicated and require implementation of very strict quality control and quality assurance protocols [16, 91-94]. In 2005, a dynamic tumor tracking technique, which was functional on a Cyberknife robotic arm, was commercialized [95, 96]. In addition, gantry-based linear accelerators with dynamic multi-leaf collimators (MLCs) are now in use for dynamic tumor tracking implementation $[94,97,98]$. In spite of these remarkable advancements in dynamic delivery of therapeutic doses [98], such as Dynamic Multi Leaf Collimators (DMLCs), robotic accelerators and robotic couches, all of these technologies suffer from a time lag in conformity of moving tumor location with therapeutic beam. As a result of this time lag, there is a lapse between adaptations of planned and delivered dose and this adaptation can be affected adversely by increasing the system time lag and latency [99103]. Therefore, implementation of dynamic tumor tracking techniques due to the technological restrictions as well as unpredictable and complex respiratory motions, which have been shown for lung tumors, are more challenging than accomplishment of breath-hold and respiratory gating techniques $[16,90]$.

The most common and practical respiratory gating techniques and systems use external body surface tracking in order to monitor respiratory motion [104]. The non-invasive nature of these techniques, with their feasibility for implementation on a wide variety of radiotherapy patients, are main advantages of external respiratory gating systems. RPM (Varian Real-time Position Management, Varian Medical System) and AZ-733 V (Anzai Medical) are two of the most commercially utilized respiratory gating systems in radiotherapy centers, which use tracking of external body surface motion to obtain respiratory cycle signal and perform respiratory gating techniques $[105,106]$. The RPM system includes an infrared camera, a computer and a marker block and two infrared reflecting dots. In this system, the marker block places on the abdominal surface of the patient, and the position of the infrared marker are determined on the basis of the images acquired by the infrared camera. Finally, the RPM system measures the movement of infrared marker with frequency of 25 $\mathrm{Hz}$ and shows it as a respiratory signal after processing [106].

The AZ-733V system includes a control personal computer, a sensor port, pressure sensor and a belt. The pressure sensor is within the pocket of the belt worn by the patient. The system indicates pressure alterations supposed as the respiratory signals. Frequency of the AZ$733 \mathrm{~V}$ system is $40 \mathrm{~Hz}$ [106].

Another system is Synchrony ${ }^{\mathrm{TM}}$ Respiratory Tracking System (Accuray Oncology, Sunnyvale, CA) associates external markers with rectangular stereoscopic images of implanted fiducials close or in the target mass to build a pattern of the target movement [22]. The pattern is then applied to move the CyberKnife $\mathbb{}$ robotic linear accelerator to monitor and track the target, and intermittently extra X-ray images are obtained for confirmation and/or update the target movement pattern [22, 107].

3 dimensional imaging systems based on 
video cameras are also accessible for acquiring 3D plane images during radiation therapy. For instance, AlignRT utilizes three cameras composed with a projected light scheme to obtain 3 dimensional plane images, whilst C-Rad system employs a line scanning method with alone camera as well as a laser device [108]. Furthermore, a study inspected performing several inner surrogates, such as air content, lung density, and body zone for sorting of 4D $\mathrm{CT}$ and reported strict settlement with external surrogates registered via RPM [109].

In Breath-Hold (BH) technique, the patient is under exposure only in an interval time while they hold their breath. In addition, if breathholding has been done at the end of inspiration cycle, it is called Deep-Inspiration BreathHold (DIBH). BH and DIBH techniques are used to establish constant and reproducible status of the external surface body position, during simulation and treatment [110]. One of the most important advantages of the implementation of $\mathrm{BH}$ techniques is a considerable decrease in internal organ movements arising during respiration. Therefore, unwanted delivered dose to healthy and sensitive tissues can be diminished by using these techniques [6]. Currently, the most important clinical application of $\mathrm{BH}$ technique in radiotherapy centersis for lung cancer treatment and some studies have conducted implementation of $\mathrm{BH}$ technique using respiratory motion monitoring systems with and without using these systems [111, 112]. Furthermore, a reproducible CT scan in breath -hold status could be obtained for treatment planning and it could be repeated on a daily basis during radiation therapy. Several systems are accessible for monitoring respiratory procedure to aid breath-hold reproducibility. These systems are substantial for exact treatment of SBRT or SRS utilizing breath-hold techniques. These tracking systems consist of spirometers [79], reflective markers on the chest tracking by cameras [113, 114], mechanical devices tracking the torso [65], thermal sensors near nostrils [79], laser and camera devices which straightly monitor the body surface (e.g. AlignRT ${ }^{\circledR}$ and C-Rad Sentinel ${ }^{\mathrm{TM}}$ ) [22, 115], fluoroscopic images of implanted fiducials [38], strain gauges attached to the body surface [79] and implanted transponders [22].

Another device to diminish breathing-inferred tumor movement throughout radiation therapy is active breathing control (ABC) system [116]. It is exploited to confine breathing movement reproducibly and repeatedly for an interval time which could be easily sustained by patients. Respiratory is provisionally postponed in a repeatable cycle of the breathing period. Facility's operator utilizes a computer-controlled valve to close and open the air flow of the patient at a predefined point in the breathing period resulting a supervised breath hold [117]. A clip upon the nose is utilized to ban nasal respiratory and warrant that patients aspire via mouthpiece. The system of $\mathrm{ABC}$ generally digitizes respiratory volumes all over respiratory period. In this method, visual control of the respiratory period is probable. Both the inhalation and exhalation routes of patients' airstream could be provisionally banned at a predefined breathing volume and flow direction. The CT or Linac machine is turned on only while respiratory is provisionally stopped. Dawson noticed that during ABC breath holds, no movements of hepatic microcoils or diaphragm was detected on fluoroscopy [118]. Wong et al stated that in ABC scans, reproducibility of the lung and liver volumes were about within $6 \%$ and $1 \%$, respectively. They also showed that scan artifacts related with free respiratory movement were not remarked in scans with ABC [89]. Gagel presented a considerable decline of breathing movement in the lower, middle, and upper areas of the chest while $\mathrm{ABC}$ was employed [116]. For 36 patients with indecent cancerous growth of the chest subjected in their evaluation, the mean dislocation ranged from 0.24 $\mathrm{mm}$ (chest wall) to $5.25 \mathrm{~mm}$ (diaphragm) and from $0.24 \mathrm{~mm}$ (chest wall/tracheal bifurca- 
tion) to $3.5 \mathrm{~mm}$ (diaphragm) for normal inspiration and expiration and shallow breathing, respectively [116].

In addition of $\mathrm{ABC}$ and $\mathrm{BH}$ techniques, $\mathrm{DIBH}$ technique is considered and used for left breast cancer radiotherapy. Performing DIBH technique leads to an increase in lung volume and as a result the left breast and cardiac tissue are being far apart; therefore, the delivered dose to the cardiac tissue witnesses a reduction by partial or complete exclusion of cardiac tissue from the treatment field. Furthermore, implementation of DIBH technique with an increase in lung volume will lead to reducing lung density; thus, relative delivered dose to lung will be diminished [119]. One of the most significant difficulties in radiation therapy planning patients with left side breast cancer is increasing of delivered dose to cardiac tissue, especially when Internal Mammary Chain (IMC) is located inside the target volume. Furthermore, recent studies have shown an increase in survival fraction among patients where their IMC lymph nodes are within the treatment fields $[120,121]$. Therefore, there has been much effort involved in exposing IMC lymph nodes along with protection of cardiac tissue by implementation of respiratory gating. In the meantime, some investigations have shown that implementation of DIBH technique on left sided breast cancer patients treated with tangential fields without any compromise in target volume coverage would lead to decreasing cardiac dose [122, 123].

A spirometer is the most common device for monitoring of a patient's respiratory cycle to perform DIBH technique in an active way. In performing active DIBH technique, the entry and exit of air to the patient's lungs is performed under computer control. Therefore, implementation of this technique is not based on the patient's ability for breath-holding [73]. Meanwhile, some other methods such as monitoring the position of lateral tattoos [124], using a real-time skin to surface distance system to monitor the anterior surface of the patient's body [124] and using magnetic transducers connected to the chest of patients [72] have been surveyed in various studies to implement the voluntary DIBH technique. Nevertheless, the weakness of the voluntary DIBH technique is relying on the patient's ability for independent breath holding [125].

Many studies carried out on respiratory gating and implementation of DIBH technique. In 2005, the study conducted by Vander Laan et al. shows that employment of wide tangential fields, in free breathing conditions, is the reason for increasing cardiac and lung doses. Moreover, by implementation of DIBH techniques, it is possible to utilize the potential benefits using narrower tangential techniques along with minimization of the cardiac dose [126]. Stranzl and Zurl in 2008 showed that performing DIBH technique, during breast cancer radiotherapy, brings considerable volume of cardiac tissue out of high dose areas [127]. In addition, Stranzl et al. in 2009 have shown that implementation of DIBH technique, when using wide tangential fields for treatment of IMC lymph nodes, is beneficial for decreasing heart tissue dose. Rochet et al. in 2014 have mentioned that DIBH technique should be operative as a routine technique for all left breast cancer patients, since implementation of DIBH is associated with potentially reducing of cardiac dose [128]. Moreover, Walston et al. in 2015 and Tanguturi et al. in 2016 showed that implementation of DIBH technique on left breast cancer patients reduces the maximum and average absorbed dose of the cardiac tissue, considerably [87, 129].

Finally, it should be noticed that several factors must be considered based on electing respiratory depth and phase at which to have patient's breathe holding. As early mentioned, the end of exhalation phase is the most likely reproducible part $[10,66,116,130]$. In addition, Nakamura et al. have shown that a $5 \mathrm{~mm}$ internal margin is essential to consider for alterations in GTV (pancreas) position with re- 
peated, video-coached breath holds at the end of expiration [131]. However, not all patients can sustain repeatedly holding their breath particularly at the end of exhalation [132]. The end of inhalation phase is not as repeatable as the end of exhalation phase, but volume of the lungs are larger at deep inhalations modifying the DVH of lung [84]. While acquisition of CT simulation, breath hold volumes might vary from volumes of free breathing, even at the same phases $[4,133]$. It is necessary that CT simulation be obtained at the same method as dose delivery will be accomplished.

\section{Conclusion}

In radiotherapy treatment of tumor tissues located in the thorax and abdominal regions, respiration is the most important cause of difference between planned doses and delivered. Tracking of respiratory motion by respiratory gating systems is one of the most efficient and cheapest methods used to compensate respiratory motions. Movement model could be anticipated through breathing-associated computed tomography (4D-CT) images carried out former to the dose delivery. Nevertheless, the feasible alterations in patient's respiration require real-time remote monitoring of tumor site while irradiancy. It could be done with fluoroscopic imaging from seeded fiducial markers or with electromagnetic identification of transponders (beacons) planted in the tumor neighborhood. Monitoring of surface body (thoraco-abdominal surface) motion permits to estimate cancerous growth movement, but establishment of external-internal association is necessary. However, such scanners could be utilized for gating, they also notify therapists from respiratory disorders containing coughs and sneezes and allow them to interfere in the therapy as needful. Furthermore, new systems utilizing particle rays for volumetric or planar imaging are under progression. Difficulty of motion target irradiation is attempted to be dissolved by some ways, including gating, rescanning, gated rescanning or tumor tracking.
These ways have been still incomplete and a lot of work has to be done to improve them.

At the same time, patients suffering from breast cancer experience a considerable decline in heart delivered dose by performing DIBH technique. Furthermore, it seems that $\mathrm{BH}$ and DIBH techniques are the optimal methods to perform respiratory gating for patients and departments, as it involves no significant increases in workload, cost or education. Finally, to consider the clinical performance benefits of gated radiotherapy, it is predictable that these systems will be used for treatment of all thorax and abdominal area tumors, in all radiotherapy centers in the near future, provided that there is access to adequate equipment.

\section{Acknowledgment}

The authors are thankful to Mashhad University of Medical Sciences for financial support of this work.

\section{Conflict of Interest}

None

\section{References}

1. Tortora GJ, Derrickson BH. Principles of anatomy and physiology. New Jersey: John Wiley \& Sons; 2008.

2. Benchetrit G. Breathing pattern in humans: diversity and individuality. Respir Physiol. 2000;122:123-9. PubMed PMID: 10967339.

3. McClelland JR, Hughes S, Modat M, Qureshi A, Ahmad $S$, Landau $D$, et al. Inter-fraction variations in respiratory motion models. Phys Med Biol. 2010;56:251. doi: 10.1088/0031-9155/56/1/015 .

4. Keall PJ, Mageras GS, Balter JM, Emery RS, Forster KM, Jiang SB, et al. The management of respiratory motion in radiation oncology report of AAPM Task Group 76. Med Phys. 2006;33:3874-900. doi: 10.1118/1.2349696. PubMed PMID: 17089851.

5. Langen KM, Jones DT. Organ motion and its management. Int J Radiat Oncol Biol Phys. 2001;50:265-78. PubMed PMID: 11316572.

6. Alnowami MR, Hagi SK. The battle against respiration-induced organ motion in external beam radiotherapy. Saudi Med J. 2014;35:651-62. PubMed PMID: 25028220.

7. Liu HH, Balter P, Tutt T, Choi B, Zhang J, Wang C, et al. Assessing respiration-induced tumor motion and internal target volume using four-dimensional computed tomography for radiotherapy of lung cancer. Int J Radiat Oncol Biol 
Phys. 2007;68:531-40. doi: 10.1016/j.jrobp.2006.12.066. PubMed PMID: 17398035.

8. Brandner ED, Wu A, Chen H, Heron D, Kalnicki S, Komanduri $\mathrm{K}$, et al. Abdominal organ motion measured using 4D CT. Int J Radiat Oncol Biol Phys. 2006;65:554-60. doi: 10.1016/j.ijrobp.2005.12.042. PubMed PMID: 16690437.

9. Mageras GS, Pevsner A, Yorke ED, Rosenzweig KE, Ford EC, Hertanto A, et al. Measurement of lung tumor motion using respiration-correlated CT. Int J Radiat Oncol Biol Phys. 2004;60:933-41. doi: 10.1016/j.jirobp.2004.06.021. PubMed PMID: 15465212.

10. Seppenwoolde $Y$, Shirato H, Kitamura K, Shimizu S, Van Herk M, Lebesque JV, et al. Precise and real-time measurement of 3D tumor motion in lung due to breathing and heartbeat, measured during radiotherapy. Int J Radiat Oncol Biol Phys. 2002;53:822-34. PubMed PMID: 12095547.

11. Shimizu S, Shirato H, Ogura S, Akita-Dosaka H, Kitamura $\mathrm{K}$, Nishioka T, et al. Detection of lung tumor movement in real-time tumor-tracking radiotherapy. Int J Radiat Oncol Biol Phys. 2001;51:304-10. PubMed PMID: 11567803.

12. Shirato $H$, Shimizu S, Kunieda T, Kitamura K, Van Herk $M$, Kagei $K$, et al. Physical aspects of a real-time tumortracking system for gated radiotherapy. Int J Radiat Oncol Biol Phys. 2000;48:1187-95. PubMed PMID: 11072178.

13. Davies SC, Hill AL, Holmes RB, Halliwell M, Jackson PC. Ultrasound quantitation of respiratory organ motion in the upper abdomen. Br J Radiol. 1994;67:1096-102. doi: 10.1259/0007-1285-67-803-1096. PubMed PMID: 7820402.

14. Hugo G, Vargas C, Liang J, Kestin L, Wong JW, Yan D. Changes in the respiratory pattern during radiotherapy for cancer in the lung. Radiother Oncol. 2006;78:326-31. doi: 10.1016/j.radonc.2006.02.015. PubMed PMID: 16564592.

15. Mageras GS, Yorke E, Rosenzweig K, Braban L, Keatley $E$, Ford $E$, et al. Fluoroscopic evaluation of diaphragmatic motion reduction with a respiratory gated radiotherapy system. J Appl Clin Med Phys. 2001;2:191-200. doi: 10.1120/1.1409235. PubMed PMID: 11686740. PubMed PMCID: PMC5726007.

16. Nøttrup TJ, Korreman SS, Pedersen AN, Aarup LR, Nyström $\mathrm{H}$, Olsen $\mathrm{M}$, et al. Intra-and interfraction breathing variations during curative radiotherapy for lung cancer. Radiother Oncol. 2007;84:40-8. doi: 10.1016/j.radonc.2007.05.026.

17. Shimizu S, Shirato H, Kagei K, Nishioka T, Bo X, DosakaAkita $\mathrm{H}$, et al. Impact of respiratory movement on the computed tomographic images of small lung tumors in three-dimensional (3D) radiotherapy. Int J Radiat Oncol Biol Phys. 2000;46:1127-33. PubMed PMID: 10725622.

18. Shen S, Duan J, Fiveash JB, Brezovich IA, Plant BA, Spencer $\mathrm{SA}$, et al. Validation of target volume and position in respiratory gated CT planning and treatment. Med Phys. 2003;30:3196-205. doi: 10.1118/1.1626121. PubMed PMID: 14713086.
19. Zaidi $H$. Recent developments and future trends in nuclear medicine instrumentation. Z Med Phys. 2006;16:5-17. PubMed PMID: 16696367.

20. Yamamoto T, Langner U, Loo Jr BW, Shen J, Keall PJ. Retrospective analysis of artifacts in four-dimensional CT images of 50 abdominal and thoracic radiotherapy patients. Int J Radiat Oncol Biol Phys. 2008;72:1250-8. doi: 10.1016/j.jrobp.2008.06.1937. PubMed PMID: 18823717. PubMed PMCID: PMC2583232.

21. Wambersie A. Prescribing, recording and reporting photon beam therapy (supplement to ICRU Report 50). ICRU report. 1999;62.

22. Glide-Hurst CK, Chetty IJ. Improving radiotherapy planning, delivery accuracy, and normal tissue sparing using cutting edge technologies. J Thorac Dis. 2014;6:30318. doi: 10.3978/j.issn.2072-1439.2013.11.10. PubMed PMID: 24688775.PubMed PMCID: PMC3968554.

23. Nehmeh SA, Erdi YE, Pan T, Yorke E, Mageras GS, Rosenzweig KE, et al. Quantitation of respiratory motion during 4D-PET/CT acquisition. Med Phys. 2004;31:1333-8. doi: 10.1118/1.1739671. PubMed PMID: 15259636.

24. Boutchko R, Balakrishnan K, Reutter BW, Gullberg GT, editors. Patient motion correction in computed tomography by reconstruction on a moving grid. IEEE Nuclear Science Symposium Conference Record; Honolulu, HI, USA: IEEE; 2007. doi: 10.1109/nssmic.2007.4436702.

25. Sonke JJ, Lebesque J, Van Herk M. Variability of fourdimensional computed tomography patient models. Int $J$ Radiat Oncol Biol Phys. 2008;70:590-8. doi: 10.1016/j. ijrobp.2007.08.067. PubMed PMID: 18037579.

26. Stam MK, Van Vulpen M, Barendrecht MM, Zonnenberg BA, Intven M, Crijns SP, et al. Kidney motion during free breathing and breath hold for MR-guided radiotherapy. Phys Med Biol. 2013;58:2235-45. doi: 10.1088/00319155/58/7/2235. PubMed PMID: 23475278.

27. Ruan D, Fessler JA, Balter JM, Keall PJ. Real-time profiling of respiratory motion: baseline drift, frequency variation and fundamental pattern change. Phys Med Biol. 2009;54:4777-92. doi: 10.1088/0031-9155/54/15/009. PubMed PMID: 19622852.

28. Siochi RA, Kim Y, Bhatia S. Tumor control probability reduction in gated radiotherapy of non-small cell lung cancers: a feasibility study. J Appl Clin Med Phys. 2014;16:4444. doi: 10.1120/jacmp.v16i1.4444. PubMed PMID: 25679148. PubMed PMCID: PMC5689977.

29. Wolfelschneider J, Brandt T, Lettmaier S, Fietkau R, Bert C. Quantification of an external motion surrogate for quality assurance in lung cancer radiation therapy. Biomed Res Int. 2014;2014:595430. doi: 10.1155/2014/595430. PubMed PMID: 25525599. PubMed PMCID: PMC4266763.

30. Krauss A, Nill S, Tacke M, Oelfke U. Electromagnetic realtime tumor position monitoring and dynamic multileaf collimator tracking using a Siemens 160 MLC: geometric and dosimetric accuracy of an integrated system. Int $J$ Radiat Oncol Biol Phys. 2011;79:579-87. doi: 10.1016/j. 
ijrobp.2010.03.043. PubMed PMID: 20656420.

31. Nioutsikou E, Seppenwoolde Y, Symonds-Tayler JR, Heijmen B, Evans P, Webb S. Dosimetric investigation of lung tumor motion compensation with a robotic respiratory tracking system: an experimental study. Med Phys. 2008;35:1232-40. doi: 10.1118/1.2842074. PubMed PMID: 18491515.

32. Bowen SR, Nyflot MJ, Gensheimer M, Hendrickson KR, Kinahan PE, Sandison GA, et al. Challenges and opportunities in patient-specific, motion-managed and PET/CT-guided radiation therapy of lung cancer: review and perspective. Clin Trans/ Med. 2012;1:18. doi: 10.1186/2001-1326-1-18. PubMed PMID: 23369522. PubMed PMCID: PMC3560984.

33. Sharp GC, Jiang SB, Shimizu S, Shirato H. Prediction of respiratory tumour motion for real-time image-guided radiotherapy. Phys Med Biol. 2004;49:425-40. PubMed PMID: 15012011.

34. Shirato $H$, Harada T, Harabayashi T, Hida $K$, Endo $H$, Kitamura K, et al. Feasibility of insertion/implantation of 2.0-mm-diameter gold internal fiducial markers for precise setup and real-time tumor tracking in radiotherapy. Int J Radiat Oncol Biol Phys. 2003;56:240-7. doi: 10.1016/ s0360-3016(03)00076-2.

35. Harada T, Shirato H, Ogura S, Oizumi S, Yamazaki K, Shimizu S, et al. Real-time tumor-tracking radiation therapy for lung carcinoma by the aid of insertion of a gold marker using bronchofiberscopy. Cancer. 2002;95:1720-7. doi: 10.1002/cncr.10856. PubMed PMID: 12365020.

36. Shirato H, Shimizu S, Shimizu T, Nishioka T, Miyasaka K. Real-time tumour-tracking radiotherapy. Lancet. 1999;353:1331-2. doi: 10.1016/S0140-6736(99)00700-X. PubMed PMID: 10218540.

37. Shimizu S, Shirato H, Kitamura K, Shinohara N, Harabayashi T, Tsukamoto $T$, et al. Use of an implanted marker and real-time tracking of the marker for the positioning of prostate and bladder cancers. Int J Radiat Oncol Biol Phys. 2000;48:1591-7. PubMed PMID: 11121666.

38. Shirato H, Shimizu S, Kitamura K, Nishioka T, Kagei K, Hashimoto $S$, et al. Four-dimensional treatment planning and fluoroscopic real-time tumor tracking radiotherapy for moving tumor. Int J Radiat Oncol Biol Phys. 2000;48:43542. PubMed PMID: 10974459.

39. Kitamura K, Shirato H, Seppenwoolde Y, Shimizu T, Kodama $\mathrm{Y}$, Endo $\mathrm{H}$, et al. Tumor location, cirrhosis, and surgical history contribute to tumor movement in the liver, as measured during stereotactic irradiation using a real-time tumor-tracking radiotherapy system. Int $J$ Radiat Oncol Biol Phys. 2003;56:221-8. PubMed PMID: 12694842.

40. Lin T, Cervino LI, Tang $X$, Vasconcelos N, Jiang SB. Fluoroscopic tumor tracking for image-guided lung cancer radiotherapy. Phys Med Biol. 2009;54:981-92. doi: 10.1088/0031-9155/54/4/011. PubMed PMID: 19147898.

41. Brandner ED, Heron D, Wu A, Huq MS, Yue NJ, Chen H. Localizing moving targets and organs using motion-man- aged CTs. Med Dosim. 2006;31:134-40. doi: 10.1016/j. meddos.2005.12.012. PubMed PMID: 16690454.

42. Imura M, Yamazaki K, Shirato $H$, Onimaru R, Fujino $M$, Shimizu $S$, et al. Insertion and fixation of fiducial markers for setup and tracking of lung tumors in radiotherapy. Int J Radiat Oncol Biol Phys. 2005;63:1442-7. doi: 10.1016/j. ijrobp.2005.04.024. PubMed PMID: 16109463.

43. Keall P. 4-dimensional computed tomography imaging and treatment planning. Semin Radiat Oncol. 2004;14:81-90. doi: 10.1053/j.semradonc.2003.10.006. PubMed PMID: 14752736 .

44. Abdelnour AF, Nehmeh SA, Pan T, Humm JL, Vernon P, Schoder $\mathrm{H}$, et al. Phase and amplitude binning for 4DCT imaging. Phys Med Biol. 2007;52:3515-29. doi: 10.1088/0031-9155/52/12/012. PubMed PMID: 17664557.

45. Zaider M, Hanin L. Tumor control probability in radiation treatment. Med Phys. 2011;38:574-83. doi: 10.1118/1.3521406. PubMed PMID: 21452694.

46. Balter JM, Wright JN, Newell LJ, Friemel B, Dimmer S, Cheng $Y$, et al. Accuracy of a wireless localization system for radiotherapy. Int $J$ Radiat Oncol Biol Phys. 2005:61:933-7. doi: 10.1016/j.jijrobp.2004.11.009. PubMed PMID: 15708277.

47. Ravkilde T, Keall PJ, Hojbjerre K, Fledelius W, Worm E, Poulsen PR. Geometric accuracy of dynamic MLC tracking with an implantable wired electromagnetic transponder. Acta Oncol. 2011;50:944-51. doi: 10.3109/0284186X.2011.590524. PubMed PMID: 21767195.

48. Seiler PG, Blattmann H, Kirsch S, Muench RK, Schilling C. A novel tracking technique for the continuous precise measurement of tumour positions in conformal radiotherapy. Phys Med Biol. 2000;45:N103-10. PubMed PMID: 11008969.

49. Mageras GS, Mechalakos J, editors. Planning in the IGRT context: closing the loop. Semin Radiat Oncol. 2007;17(4):268-77. doi: 10.1016/j.semradonc.2007.06.002.

50. Purdie TG, Bissonnette JP, Franks K, Bezjak A, Payne D, Sie $F$, et al. Cone-beam computed tomography for on-line image guidance of lung stereotactic radiotherapy: Iocalization, verification, and intrafraction tumor position. Int $J$ Radiat Oncol Biol Phys. 2007;68:243-52. doi: 10.1016/j. ijrobp.2006.12.022. PubMed PMID: 17331671.

51. Higgins J, Bezjak A, Hope A, Panzarella T, Li W, Cho JB, et al. Effect of image-guidance frequency on geometric accuracy and setup margins in radiotherapy for locally advanced lung cancer. Int J Radiat Oncol Biol Phys. 2011;80:1330-7. doi: 10.1016/j.jijrobp.2010.04.006. PubMed PMID: 20643515.

52. Nehmeh SA, Erdi YE, Pan T, Pevsner A, Rosenzweig $\mathrm{KE}$, Yorke E, et al. Four-dimensional (4D) PET/CT imaging of the thorax. Med Phys. 2004;31:3179-86. doi: 10.1118/1.1809778. PubMed PMID: 15651600. 
53. Nehmeh SA, Erdi YE, Ling CC, Rosenzweig KE, Squire OD, Braban LE, et al. Effect of respiratory gating on reducing lung motion artifacts in PET imaging of lung cancer. Med Phys. 2002;29:366-71. doi: 10.1118/1.1448824. PubMed PMID: 11929020.

54. Hu Y, Caruthers SD, Low DA, Parikh PJ, Mutic S. Respiratory amplitude guided 4-dimensional magnetic resonance imaging. Int J Radiat Oncol Biol Phys. 2013;86:198-204. doi: 10.1016/j.jijrobp.2012.12.014.

55. Cai J, Chang Z, Wang Z, Paul Segars W, Yin FF. Fourdimensional magnetic resonance imaging (4D-MRI) using image-based respiratory surrogate: a feasibility study. Med Phys. 2011;38:6384-94. doi: 10.1118/1.3658737. PubMed PMID: 22149822; PubMed Central PMCID: PMC4108683.

56. Yang YX, Teo SK, Van Reeth E, Tan CH, Tham IW, Poh CL. A hybrid approach for fusing 4D-MRI temporal information with 3D-CT for the study of lung and lung tumor motion. Med Phys. 2015;42:4484-96. doi: 10.1118/1.4923167. PubMed PMID: 26233178.

57. Paganelli C, Summers P, Bellomi M, Baroni G, Riboldi M. Liver 4DMRI: A retrospective image-based sorting method. Med Phys. 2015;42:4814-21. doi: 10.1118/1.4927252. PubMed PMID: 26233208.

58. Glide-Hurst CK, Kim JP, To D, Hu Y, Kadbi M, Nielsen T, et al. Four dimensional magnetic resonance imaging optimization and implementation for magnetic resonance imaging simulation. Pract Radiat Oncol. 2015;5:433-42. doi: 10.1016/j.prro.2015.06.006. PubMed PMID: 26419444.

59. Stemkens B, Tijssen RH, De Senneville BD, Lagendijk JJ, Van Den Berg CA. Image-driven, model-based 3D abdominal motion estimation for MR-guided radiotherapy. Phys Med Biol. 2016;61:5335-55. doi: 10.1088/00319155/61/14/5335. PubMed PMID: 27362636.

60 . Bert C, Durante M. Motion in radiotherapy: particle therapy. Phys Med Biol. 2011;56:R113-44. doi: 10.1088/00319155/56/16/R01. PubMed PMID: 21775795.

61. Schlosser J, Salisbury K, Hristov D. Telerobotic system concept for real-time soft-tissue imaging during radiotherapy beam delivery. Med Phys. 2010;37:6357-67. doi: 10.1118/1.3515457. PubMed PMID: 21302793.

62. Langen KM, Pouliot J, Anezinos C, Aubin M, Gottschalk $A R$, Hsu IC, et al. Evaluation of ultrasound-based prostate localization for image-guided radiotherapy. Int $J$ Radiat Oncol Biol Phys. 2003;57:635-44. PubMed PMID: 14529767.

63. Harris EJ, Miller NR, Bamber JC, Symonds-Tayler JR, Evans PM. Speckle tracking in a phantom and featurebased tracking in liver in the presence of respiratory motion using 4D ultrasound. Phys Med Biol. 2010;55:336380. doi: 10.1088/0031-9155/55/12/007. PubMed PMID: 20505224.

64. Ozhasoglu C, Murphy MJ. Issues in respiratory motion compensation during external-beam radiotherapy. Int $\mathrm{J}$ Radiat Oncol Biol Phys. 2002;52:1389-99. PubMed PMID: 11955754
65. Onishi $H$, Kawakami $H$, Marino K, Komiyama T, Kuriyama $\mathrm{K}$, Araya $\mathrm{M}$, et al. A simple respiratory indicator for irradiation during voluntary breath holding: a one-touch device without electronic materials. Radiology. 2010;255:917-23. doi: 10.1148/radiol.10090890. PubMed PMID: 20501729.

66. Goossens S, Senny F, Lee JA, Janssens G, Geets X. Assessment of tumor motion reproducibility with audiovisual coaching through successive 4D CT sessions. J Appl Clin Med Phys. 2014;15:4332. doi: 10.1120/jacmp. v15i1.4332. PubMed PMID: 24423834. PubMed PMCID: PMC5711223.

67. Boutchko R, Reutter BW, Saloner D, Gullberg GT, editors. Correlating motion of internal organs with the displacements of fiducial markers during respiration. IEEE Nuclear Science Symposium Conference Record; Dresden, Germany: IEEE; 2008. doi: 10.1109/nssmic.2008.4774107.

68. Wolthaus JW, Van Herk M, Muller SH, Belderbos JS, Lebesque JV, De Bois JA, et al. Fusion of respirationcorrelated PET and CT scans: correlated lung tumour motion in anatomical and functional scans. Phys Med Biol. 2005;50:1569-83. doi: 10.1088/0031-9155/50/7/017. PubMed PMID: 15798344.

69. Lang N, Dawood M, Buther F, Schober 0, Schafers M, Schafers K. Organ movement reduction in PET/CT using dual-gated list-mode acquisition. Z Med Phys. 2006;16:93100. PubMed PMID: 16696375.

70. Moser T, Fleischhacker S, Schubert K, Sroka-Perez G, Karger CP. Technical performance of a commercial laser surface scanning system for patient setup correction in radiotherapy. Phys Med. 2011;27:224-32. doi: 10.1016/j. ejmp.2010.10.005. PubMed PMID: 21055989.

71. Brahme A, Nyman P, Skatt B. 4D laser camera for accurate patient positioning, collision avoidance, image fusion and adaptive approaches during diagnostic and therapeutic procedures. Med Phys. 2008;35:1670-81. doi: 10.1118/1.2889720. PubMed PMID: 18561642.

72. Remouchamps VM, Huyskens DP, Mertens I, Destine M, Van Esch A, Salamon E, et al. The use of magnetic sensors to monitor moderate deep inspiration breath hold during breast irradiation with dynamic MLC compensators. Radiother Oncol. 2007;82:341-8. doi: 10.1016/j.radonc.2006.11.015. PubMed PMID: 17207547.

73. Peng $Y$, Vedam S, Gao S, Balter P. A new respiratory monitoring and processing system based on Wii remote: proof of principle. Med Phys. 2013;40:071712. doi: 10.1118/1.4810941. PubMed PMID: 23822416.

74. Minohara S, Kanai T, Endo M, Noda K, Kanazawa M. Respiratory gated irradiation system for heavy-ion radiotherapy. Int J Radiat Oncol Biol Phys. 2000;47:1097-103. PubMed PMID: 10863083.

75. Tada T, Minakuchi K, Fujioka T, Sakurai M, Koda M, Kawase I, et al. Lung cancer: intermittent irradiation synchronized with respiratory motion--results of a pilot study. Radiology. 1998;207:779-83. doi: 10.1148/radiology.207.3.9609904. PubMed PMID: 9609904. 
76. Hara R, Itami J, Kondo T, Aruga T, Abe $\mathrm{Y}$, Ito $\mathrm{M}$, et al. Stereotactic single high dose irradiation of lung tumors under respiratory gating. Radiother Oncol. 2002;63:15963. PubMed PMID: 12063005.

77. Chang G, Chang T, Clark Jr JW, Mawlawi OR. Design and performance of a respiratory amplitude gating device for PET/CT imaging. Med Phys. 2010;37:1408-12. doi: 10.1118/1.3352835. PubMed PMID: 20443462. PubMed PMCID: PMC3810262.

78. Fung A, Li C, Torres C. TH-AB-202-07: Radar Tracking of Respiratory Motion in Real Time. Med Phys. 2016;43:3858. doi: 10.1118/1.4958071.

79. Kubo HD, Hill BC. Respiration gated radiotherapy treatment: a technical study. Phys Med Biol. 1996;41:83-91. PubMed PMID: 8685260.

80. Kubo HD, Len PM, Minohara S, Mostafavi H. Breathingsynchronized radiotherapy program at the University of California Davis Cancer Center. Med Phys. 2000;27:34653. doi: 10.1118/1.598837. PubMed PMID: 10718138.

81. Ford EC, Mageras GS, Yorke E, Rosenzweig KE, Wagman R, Ling CC. Evaluation of respiratory movement during gated radiotherapy using film and electronic portal imaging. Int J Radiat Oncol Biol Phys. 2002;52:522-31. PubMed PMID: 11872300.

82. Ramsey CR, Cordrey IL, Oliver AL. A comparison of beam characteristics for gated and nongated clinical $x$-ray beams. Med Phys. 1999;26:2086-91. doi: 10.1118/1.598723. PubMed PMID: 10535624.

83. Ramsey CR, Scaperoth D, Arwood D, Oliver AL. Clinical efficacy of respiratory gated conformal radiation therapy Med Dosim. 1999;24:115-9. PubMed PMID: 10379508.

84. Vedam SS, Keall PJ, Kini VR, Mohan R. Determining parameters for respiration-gated radiotherapy. Med Phys. 2001;28:2139-46. doi: 10.1118/1.1406524. PubMed PMID: 11695776.

85. Vedam SS, Kini VR, Keall PJ, Ramakrishnan V, Mostafavi H, Mohan R. Quantifying the predictability of diaphragm motion during respiration with a noninvasive external marker. Med Phys. 2003;30:505-13. doi: 10.1118/1.1558675. PubMed PMID: 12722802.

86. Jiang S, Berbeco R, Wolfgang J, Sharp G, Doppke K, Neicu T, et al. TH-C-J-6B-09: Image-Guided Respiration-Gated Treatment. Med Phys. 2005;32:2160-1. doi: 10.1118/1.1998653.

87. Walston S, Quick AM, Kuhn K, Rong Y. Dosimetric Considerations in Respiratory-Gated Deep Inspiration BreathHold for Left Breast Irradiation. Technol Cancer Res Treat. 2017;16:22-32. doi: 10.1177/1533034615624311. PubMed PMID: 26755749. PubMed PMCID: PMC5616111.

88. Hansen VN, Evans PM, Budgell GJ, Mott JH, Williams PC, Brugmans MJ, et al. Quality assurance of the dose delivered by small radiation segments. Phys Med Biol. 1998;43:2665-75. PubMed PMID: 9755953.

89. Wong JW, Sharpe MB, Jaffray DA, Kini VR, Robertson
JM, Stromberg JS, et al. The use of active breathing control $(A B C)$ to reduce margin for breathing motion. Int $J$ Radiat Oncol Biol Phys. 1999;44:911-9. PubMed PMID: 10386650.

90. Hoisak JD, Sixel KE, Tirona R, Cheung PC, Pignol JP. Correlation of lung tumor motion with external surrogate indicators of respiration. Int J Radiat Oncol Biol Phys. 2004;60:1298-306. doi: 10.1016/j.jijrobp.2004.07.681. PubMed PMID: 15519803.

91. Sawant A, Dieterich S, Svatos M, Keall P. Failure mode and effect analysis-based quality assurance for dynamic MLC tracking systems. Med Phys. 2010;37:6466-79. doi: 10.1118/1.3517837. PubMed PMID: 21302802. PubMed PMCID: PMC3016096.

92. Keall PJ, Kini VR, Vedam SS, Mohan R. Motion adaptive xray therapy: a feasibility study. Phys Med Biol. 2001;46:110. PubMed PMID: 11197664.

93. Poulsen PR, Schmidt ML, Keall P, Worm ES, Fledelius W, Hoffmann L. A method of dose reconstruction for moving targets compatible with dynamic treatments. Med Phys. 2012;39:6237-46. doi: 10.1118/1.4754297. PubMed PMID: 23039659.PubMed PMCID: PMC3470610.

94. Fast MF, O'Shea TP, Nill S, Oelfke U, Harris EJ. First evaluation of the feasibility of MLC tracking using ultrasound motion estimation. Med Phys. 2016;43:4628. doi: 10.1118/1.4955440. PubMed PMID: 27487879.

95. Ozhasoglu C, Saw CB, Chen H, Burton S, Komanduri K, Yue $\mathrm{NJ}$, et al. Synchrony-cyberknife respiratory compensation technology. Med Dosim. 2008;33:117-23. doi: 10.1016/j. meddos.2008.02.004. PubMed PMID: 18456163.

96. Seppenwoolde $\mathrm{Y}$, Berbeco RI, Nishioka S, Shirato $H$, Heijmen B. Accuracy of tumor motion compensation algorithm from a robotic respiratory tracking system: a simulation study. Med Phys. 2007;34:2774-84. doi: 10.1118/1.2739811. PubMed PMID: 17821984.

97. Poulsen PR, Cho B, Ruan D, Sawant A, Keall PJ. Dynamic multileaf collimator tracking of respiratory target motion based on a single kilovoltage imager during arc radiotherapy. Int J Radiat Oncol Biol Phys. 2010;77:600-7. doi: 10.1016/j.ijrobp.2009.08.030. PubMed PMID: 20133066.

98. Falk M, Munck af Rosenschold P, Keall P, Cattell H, Cho $B C$, Poulsen $P$, et al. Real-time dynamic MLC tracking for inversely optimized arc radiotherapy. Radiother Oncol. 2010;94:218-23. doi: 10.1016/j.radonc.2009.12.022. PubMed PMID: 20089322. PubMed PMCID: PMC2855882.

99. Ernst F, Schweikard A. Forecasting respiratory motion with accurate online support vector regression (SVRpred). Int J Comput Assist Radiol Surg. 2009;4:439-47. doi: 10.1007/ s11548-009-0355-5. PubMed PMID: 20033526.

100.Ruan D, Keall P. Online prediction of respiratory motion: multidimensional processing with low-dimensional feature learning. Phys Med Biol. 2010;55:301125. doi: 10.1088/0031-9155/55/11/002. PubMed PMID: 20442460. PubMed PMCID: PMC2975024. 
101.Vandermeer AD, Alasti $H$, Cho YB, Norrlinger B. Investigation of the dosimetric effect of respiratory motion using four-dimensional weighted radiotherapy. Phys Med Biol. 2007;52:4427-48. doi: 10.1088/0031-9155/52/15/005. PubMed PMID: 17634642.

102.Vedam S, Docef A, Fix M, Murphy M, Keall P. Dosimetric impact of geometric errors due to respiratory motion prediction on dynamic multileaf collimator-based four-dimensional radiation delivery. Med Phys. 2005;32:1607-20. doi: 10.1118/1.1915017. PubMed PMID: 16013720.

103. Webb S. Quantification of the fluence error in the motioncompensated dynamic MLC (DMLC) technique for delivering intensity-modulated radiotherapy (IMRT). Phys Med Biol. 2006;51:L17-21. doi: 10.1088/0031-9155/51/7/L01. PubMed PMID: 16552094.

104.Berbeco RI, Mostafavi H, Sharp GC, Jiang SB. Towards fluoroscopic respiratory gating for lung tumours without radiopaque markers. Phys Med Biol. 2005;50:448190. doi: 10.1088/0031-9155/50/19/004. PubMed PMID: 16177484.

105.Kini VR, Vedam SS, Keall PJ, Patil S, Chen C, Mohan R. Patient training in respiratory-gated radiotherapy. Med Dosim. 2003;28:7-11. doi: 10.1016/S0958-3947(02)00136X. PubMed PMID: 12747612.

106.Otani Y, Fukuda I, Tsukamoto N, Kumazaki Y, Sekine $\mathrm{H}$, Imabayashi $\mathrm{E}$, et al. A comparison of the respiratory signals acquired by different respiratory monitoring systems used in respiratory gated radiotherapy. Med Phys. 2010;37:6178-86. doi: 10.1118/1.3512798. PubMed PMID: 21302774.

107.Dawson LA, Sharpe MB. Image-guided radiotherapy: rationale, benefits, and limitations. Lancet Oncol. 2006;7:84858. doi: 10.1016/S1470-2045(06)70904-4. PubMed PMID: 17012047.

108.Willoughby T, Lehmann J, Bencomo JA, Jani SK, Santanam L, Sethi A, et al. Quality assurance for nonradiographic radiotherapy localization and positioning systems: report of Task Group 147. Med Phys. 2012;39:1728-47. doi: 10.1118/1.3681967. PubMed PMID: 22482598.

109.Li R, Lewis JH, Cervino LI, Jiang SB. 4D CT sorting based on patient internal anatomy. Phys Med Biol. 2009;54:482133. doi: 10.1088/0031-9155/54/15/012. PubMed PMID: 19622855

110.Hayden AJ, Rains M, Tiver K. Deep inspiration breath hold technique reduces heart dose from radiotherapy for left-sided breast cancer. J Med Imaging Radiat Oncol. 2012;56:464-72. doi: 10.1111/j.1754-9485.2012.02405.x. PubMed PMID: 22883657.

111.Berson AM, Emery R, Rodriguez L, Richards GM, Ng T, Sanghavi S, et al. Clinical experience using respiratory gated radiation therapy: comparison of free-breathing and breath-hold techniques. Int $J$ Radiat Oncol Biol Phys. 2004;60:419-26. doi: 10.1016/j.jirobp.2004.03.037. PubMed PMID: 15380575.

112.Berbeco RI, Nishioka S, Shirato H, Chen GT, Jiang SB.
Residual motion of lung tumours in gated radiotherapy with external respiratory surrogates. Phys Med Biol. 2005;50:3655-67. doi: 10.1088/0031-9155/50/16/001. PubMed PMID: 16077219.

113.Murphy MJ, Martin D, Whyte R, Hai J, Ozhasoglu C, Le QT. The effectiveness of breath-holding to stabilize lung and pancreas tumors during radiosurgery. Int $J$ Radiat Oncol Biol Phys. 2002;53:475-82. PubMed PMID: 12023152.

114.Gierga DP, Brewer J, Sharp GC, Betke M, Willett CG, Chen GT. The correlation between internal and external markers for abdominal tumors: implications for respiratory gating. Int J Radiat Oncol Biol Phys. 2005;61:1551-8. doi: 10.1016/j.jirobp.2004.12.013. PubMed PMID: 15817361.

115.Li G, Arora NC, Xie H, Ning H, Lu W, Low D, et al. Quantitative prediction of respiratory tidal volume based on the external torso volume change: a potential volumetric surrogate. Phys Med Biol. 2009;54:1963-78. doi: 10.1088/0031-9155/54/7/007. PubMed PMID: 19265201.

116.Gagel B, Demirel C, Kientopf A, Pinkawa M, Piroth M, Stanzel S, et al. Active breathing control (ABC): determination and reduction of breathing-induced organ motion in the chest. Int J Radiat Oncol Biol Phys. 2007;67:742-9. doi: 10.1016/j.jirobp.2006.09.052. PubMed PMID: 17197133.

117.Giraud P, Houle A. Respiratory gating for radiotherapy: main technical aspects and clinical benefits. ISRN Pulmonology. 2013;2013. doi: 10.1155/2013/519602.

118.Dawson LA, Brock KK, Kazanjian S, Fitch D, McGinn CJ, Lawrence TS, et al. The reproducibility of organ position using active breathing control $(A B C)$ during liver radiotherapy. Int J Radiat Oncol Biol Phys. 2001;51:1410-21. PubMed PMID: 11728702.

119.Vikstrom J, Hjelstuen MH, Mjaaland I, Dybvik KI. Cardiac and pulmonary dose reduction for tangentially irradiated breast cancer, utilizing deep inspiration breath-hold with audio-visual guidance, without compromising target coverage. Acta Oncol. 2011;50:42-50. doi: 10.3109/0284186X.2010.512923. PubMed PMID: 20843181.

120.Chen RC, Lin NU, Golshan M, Harris JR, Bellon JR. Internal mammary nodes in breast cancer: diagnosis and implications for patient management a systematic review. $J$ Clin Oncol. 2008;26:4981-9.

121.Veronesi U, Arnone P, Veronesi P, Galimberti V, Luini A, Rotmensz N, et al. The value of radiotherapy on metastatic internal mammary nodes in breast cancer. Results on a large series. Ann Oncol. 2008;19:1553-60. doi: 10.1093/ annonc/mdn183. PubMed PMID: 18467318.

122.Stranzl H, Zurl B, Langsenlehner T, Kapp KS. Wide tangential fields including the internal mammary lymph nodes in patients with left-sided breast cancer. Influence of respiratory-controlled radiotherapy (4D-CT) on cardiac exposure. Strahlenther Onkol. 2009;185:155-60. doi: 10.1007/ s00066-009-1939-2. PubMed PMID: 19330291.

123. Remouchamps VM, Vicini FA, Sharpe MB, Kestin LL, Martinez AA, Wong JW. Significant reductions in heart and 
lung doses using deep inspiration breath hold with active breathing control and intensity-modulated radiation therapy for patients treated with locoregional breast irradiation. Int J Radiat Oncol Biol Phys. 2003;55:392-406. PubMed PMID: 12527053.

124.Jensen C, Urribarri J, Cail D, Rottmann J, Mishra P, Lingos $T$, et al. Cine EPID evaluation of two non-commercial techniques for DIBH. Med Phys. 2014;41:021730. doi: 10.1118/1.4862835. PubMed PMID: 24506621; PubMed Central PMCID: PMC3977833.

125. Murphy MJ. Adaptive motion compensation in radiotherapy. Florida: CRC Press; 2011.

126.Van Der Laan HP, Dolsma WV, Van't Veld AA, Bijl HP, Langendijk JA. Comparison of normal tissue dose with three-dimensional conformal techniques for breast cancer irradiation including the internal mammary nodes. Int $\mathrm{J}$ Radiat Oncol Biol Phys. 2005;63:1522-30. doi: 10.1016/j. ijrobp.2005.04.027. PubMed PMID: 15994027.

127.Stranzl H, Zurl B. Postoperative irradiation of left-sided breast cancer patients and cardiac toxicity. Does deep inspiration breath-hold (DIBH) technique protect the heart? Strahlenther Onkol. 2008;184:354-8. doi: 10.1007/ s00066-008-1852-0. PubMed PMID: 19016033.

128. Rochet N, Drake JI, Harrington K, Wolfgang JA, Napolitano B, Sadek BT, et al. Deep inspiration breath-hold technique in left-sided breast cancer radiation therapy: Evaluating cardiac contact distance as a predictor of cardiac exposure for patient selection. Pract Radiat Oncol. 2015;5:e127-
34. doi: 10.1016/j.prro.2014.08.003. PubMed PMID: 25413399.

129. Tanguturi SK, Lyatskaya Y, Chen Y, Catalano PJ, Chen MH, Yeo W-P, et al. Prospective assessment of deep inspiration breath-hold using 3-dimensional surface tracking for irradiation of left-sided breast cancer. Pract Radiat Oncol. 2015;5:358-65. doi: 10.1016/j.prro.2015.06.002.

130.George R, Chung TD, Vedam SS, Ramakrishnan V, Mohan $\mathrm{R}$, Weiss $\mathrm{E}$, et al. Audio-visual biofeedback for respiratorygated radiotherapy: impact of audio instruction and audiovisual biofeedback on respiratory-gated radiotherapy. Int $J$ Radiat Oncol Biol Phys. 2006;65:924-33. doi: 10.1016/j. ijrobp.2006.02.035. PubMed PMID: 16751075.

131.Nakamura M, Shibuya K, Shiinoki T, Matsuo Y, Nakamura A, Nakata $M$, et al. Positional reproducibility of pancreatic tumors under end-exhalation breath-hold conditions using a visual feedback technique. Int J Radiat Oncol Biol Phys. 2011;79:1565-71. doi: 10.1016/j.jirobp.2010.05.046. PubMed PMID: 20832187.

132.Burnett SS, Sixel KE, Cheung PC, Hoisak JD. A study of tumor motion management in the conformal radiotherapy of lung cancer. Radiother Oncol. 2008;86:77-85. doi: 10.1016/j.radonc.2007.11.017. PubMed PMID: 18077031.

133.Hunjan S, Starkschall G, Prado K, Dong L, Balter P. Lack of correlation between external fiducial positions and internal tumor positions during breath-hold CT. Int $J$ Radiat Oncol Biol Phys. 2010;76:1586-91. doi: 10.1016/j. ijrobp.2009.08.008. PubMed PMID: 20133074. 